\title{
The semantics of Turkish numeral constructions ${ }^{1}$
}

\author{
Yağmur SA $\breve{G}$ - Rutgers, The State University of New Jersey
}

\begin{abstract}
This paper explores Turkish numeral constructions, which have typologically two interesting properties: (i) the existence of an optional classifier, (ii) the incompatibility of plurals with them. I argue that numerals are modifiers of type $\langle<\mathrm{e}, \mathrm{t}\rangle,\langle\mathrm{e}, \mathrm{t}\rangle\rangle$ defined only for atomic properties (Ionin and Matushansky 2006). The explanation rests on the semantics of bare singulars proposed to denote sets of atoms (contra Bale et al. 2010), and the semantics of the classifier claimed to be a partial identity function presupposing atomic properties.
\end{abstract}

Keywords: numerals, atomicity, number neutrality, plurality, kinds, optional classifiers.

\section{Introduction}

Turkish numeral constructions have two typologically interesting properties: (i) the existence of an optional classifier, tane, and (ii) the incompatibility of plurals with them as shown in (1a) and (1b) below. ${ }^{2}$

$$
\begin{aligned}
& \text { a. iki (tane) kitap } \\
& \text { two CL book } \\
& \text { 'two books' }
\end{aligned}
$$
b. *iki (tane) kitap-lar
two CL book-PL 'two books'

This paper argues that Turkish numerals are modifiers of type $<<\mathrm{e}, \mathrm{t}\rangle,<\mathrm{e}, \mathrm{t}\rangle\rangle$ that combine with atomic properties as proposed by Ionin and Matushansky (2006), contra Bale et al. (2010) where they are treated as restrictive modifiers. The analysis revolves around the semantics of bare singulars which are proposed to denote sets of atoms here instead of being number neutral as claimed in Bale et al. (2010). In addition, the classifier tane is claimed to be a partial identity function presupposing atomic properties.

Notes on terminology: I refer to nouns unmarked for number as bare singulars, whereas I refer to nouns inflected with -lAr as bare plurals following the convention in Carlson (1977) and neoCarlsonian studies for English bare plurals. As stated above, this paper shows that singularity of bare singulars is not only a morphological but also a semantic property contrasting with the accounts positing a number neutral denotation to them. Since Turkish lacks an overt definite article, both bare singulars and bare plurals can freely occupy argument positions, as opposed to English in which bare singulars do not have this freedom.

This paper is organized as follows. Section 2 introduces two distinct accounts of the semantics

\footnotetext{
${ }^{1}$ I am indebted to Veneeta Dayal, Simon Charlow and Mark Baker for their generous comments on this work. I also thank Ömer Demirok, Jess Law, Lucas Champollion, and Haoze Li for helpful discussions.

${ }^{2}$ Turkish has two classifiers besides group denoting ones. One is tane, compatible with all count nouns, and the other is adet, compatible with non-human count nouns. In this study, I will only refer to tane since the distribution of both classifiers is the same. They are considered to be classifiers since they have similar properties as the classifiers in other languages. As defined in Kim (2009), (i) classifiers are only compatible with count nouns whereas measure words are compatible with both count and mass nouns, (ii) they cannot be modified by an adjective as opposed to measure words, and (iii) they can be used with quantifiers compatible with count nouns.
} 
of Turkish numerals and clarifies the relevant details. Section 3 provides an analysis for the semantics of bare singulars showing that they denote atomic properties. Section 4 incorporates the optional classifier tane into the overall picture. Section 5 concludes.

\section{The Semantics of Numerals}

Numerals have been treated as both determiners of type $<<\mathrm{e}, \mathrm{t}\rangle,<<\mathrm{e}, \mathrm{t}\rangle, \mathrm{t}\rangle>$ (Bennett 1974, among others) and predicates of type $<\mathrm{e}, \mathrm{t}>$ (Partee 1987, Link 1987, Landman 1989, among others). Among the ones who treat numerals as predicates, Link (1987) analyzes them as restrictive modifiers. However, all of these works focus only on simplex numerals. On the other hand, Ionin and Matushansky (2006) (I\&M, henceforth) treat numerals as modifiers of type $\langle<\mathrm{e}, \mathrm{t}\rangle,\langle\mathrm{e}, \mathrm{t}\rangle\rangle$ the lexical complement of which has to be atomic. Their illustration is

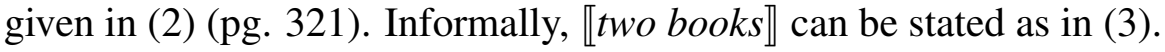

$$
\begin{array}{ll}
\text { a. } & \llbracket t w o \rrbracket=\lambda P \lambda x \exists S[\Pi(S)(x) \wedge|S|=2 \wedge \forall s \in S P(s)] \\
\text { b. } & \prod(S)(x)=1 \text { iff } \\
& S \text { is a cover of } x, \text { and } \\
& \forall z, y \in S\left[z=y \vee \neg \exists a\left[a \leq_{i} z \wedge a \leq_{i} y\right]\right]
\end{array}
$$

c. A set of individuals $C$ is a cover of a plural individual $X$ iff $X$ is the sum of all members of $C: \sqcup C=X$

(3) $\quad \lambda x \in D_{e} . x$ is a plural individual divisible into 2 non-overlapping individuals $p_{i}$ such that their sum is $x$ and each $p_{i}$ is a book.

I\&M show that if simplex numerals were determiners it would not be possible to derive the semantics of complex numerals, like two hundred. Namely, if hundred (presumably of type $<<\mathrm{e}, \mathrm{t}\rangle,<<\mathrm{e}, \mathrm{t}\rangle, \mathrm{t}\rangle>$ ) combined with books (of type $<\mathrm{e}, \mathrm{t}\rangle$ ) first, the resulting NP would be a generalized quantifier of type $<<e, t>, t>$. Consequently, this NP could not combine with another numeral. They also show that treating numerals as predicates of type $\langle\mathrm{e}, \mathrm{t}\rangle$ faces the same problem; the semantic composition of numerals would fail in a complex numeral construction. This time, the problem is not about types, but predicate modification would result in incorrect truth-conditions. Namely, the NP two hundred books would denote the empty set since for no $x$ it is the case that the set of atoms is equal to both two and hundred simultaneously.

On the other hand, in I\&M's analysis complex numerals are derived fully compositionally, i.e. hundred books being of type $<\mathrm{e}, \mathrm{t}\rangle$ can be an argument to two that is of type $<<\mathrm{e}, \mathrm{t}\rangle,<\mathrm{e}, \mathrm{t}\rangle>$.

The crucial part of their claim is that they treat English $-s$ in numeral constructions as number agreement (semantic concord) rather than being a genuine plural marker. They claim that true plurals cannot combine with numerals because a plural noun such as books denotes a set of individuals $x$, where each $x$ is a plurality of books, and these pluralities do not necessarily have the same cardinality. In other words, books in two books has to be semantically singular, only denoting a set of atomic individuals.

There are two main approaches to Turkish numerals. One is I\&M's (2006) view of numerals 
as sketched above. They claim that languages like Turkish, where numerals combine with singular forms of nouns, constitute evidence for the atomic requirement of numerals. Their claim is based on the assumption that Turkish bare singulars denote sets of atoms.

On the other hand, Bale et al. (2010) argue against this view and treat Turkish numerals as restrictive modifiers combining with nouns via subsective modification, following Link (1987). Namely, numerals in Turkish are considered as functions from number neutral sets to one of their subsets which consists of all and only the groups that are composed of $n$ (number denoted by the numeral) non-overlapping (atomic) minimal parts. The idea is that Turkish bare singulars are number neutral, i.e. inclusive of atoms and their pluralities, instead of denoting sets of atoms. Their semantics of Turkish numerals is illustrated below (Bale et al. 2010: pg. 10):

$$
\begin{array}{lc}
\text { a. } & \llbracket t w o \rrbracket=\lambda P_{p l} \cdot\left\{x: x \in P_{p l} \& \exists Y[Y \in \operatorname{PART}(x) \&|Y|=2 \&\right. \\
& \left.\left.\forall z\left[z \in Y \rightarrow z \in \operatorname{MIN}\left(P_{p l}\right)\right]\right]\right\} \\
\text { b. } & \text { A predicate } Q \text { is of type } P_{p l} \text { iff } \forall x, y \in Q[x \oplus y \in Q] \\
\text { c. } & \operatorname{MIN}(P) \text { is defined iff } \\
& \forall x, y[[x, y \in P \& \neg \exists z[z \in P \&[z<y \vee z<x]]] \rightarrow x \wedge y=0] . \\
& \text { When defined } \operatorname{MIN}(P)=\{x: x \in P \& \neg \exists z[z<x]\} .
\end{array}
$$

In this paper, I aim at showing that I\&M's analysis should be favored over Bale et al.'s. Adopting this view of numerals explains the core facts of Turkish numeral constructions if the following hold: (i) Turkish bare singulars are strict singulars denoting sets of atoms, (ii) Turkish numeral constructions lack plural agreement, and (iii) the classifier tane is a partial identity function defined only for atomic properties. Following I\&M in that Turkish numeral constructions lack plural agreement unlike the English ones, I will motivate and justify the atomicity of bare singulars and the semantics of the classifier below.

\section{Turkish Bare Singulars as Atomic Properties}

Thanks to the seminal work of Link (1983), the mereological treatment of pluralities has become a well-established tradition in the semantic literature, where the domain of individuals $\left(D_{e}\right)$ has been assumed to include atoms and their closure under the sum operator $\oplus$. For example, the complete atomic join semilattice with $\mathrm{a}, \mathrm{b}$, and $\mathrm{c}$ as singular individuals include the atoms $\mathrm{a}, \mathrm{b}, \mathrm{c}$ and the pluralities $\mathrm{a} \oplus \mathrm{b}, \mathrm{a} \oplus \mathrm{c}, \mathrm{b} \oplus \mathrm{c}$, and $\mathrm{a} \oplus \mathrm{b} \oplus \mathrm{c}$.

Bale et al. (2010) argue that Turkish bare singulars denote number neutral sets, inclusive of atoms and pluralities (see also Görgülü 2012). For example, if in a model a, b, and c are the books, the Turkish noun kitap 'book' denotes the set $\{a, b, c, a \oplus b, a \oplus c, b \oplus c, a \oplus b \oplus c\}$. Their claim is based on the neutral interpretation of bare singulars in the predicate position as in (5a). In addition, bare singulars in Turkish are also known as having number neutral interpretations in non-case marked direct object positions as exemplified in (5b).
a. Ali ve Merve çocuk.
Ali and Merve child
'Ali and Merve are children.'

b. Ali kitap oku-du.

Ali book read-PAST

'Ali read a book/books.' 
Despite what these cases seem to suggest, I argue that bare singulars in Turkish denote sets of atoms only, i.e. $\llbracket k i t a p \rrbracket=\{a, b, c\}$. My claim is based on their singularity in argument positions and their singular kind denotations. I will first illustrate the strict singularity of bare singulars and then explain the apparent number neutrality in the cases shown above, which I claim to follow from their singular kind denotations.

\subsection{Strict singularity in argument positions}

Bare singulars in Turkish are interpreted as strictly singular and definite in subject and casemarked object positions as shown in (6a) and (6b), respectively. This constitutes evidence for their atomicity. Namely, if they denoted number neutral sets inclusive of atoms and pluralities, we would expect to get number neutral interpretations in these examples.
a. Çocuk ev-e koş-tu.
child home-DAT run-PAST
'The child ran home.'
Not: 'The children ran home.'
b. Ali kitab-1 oku-du.
Ali book-ACC read-PAST
'Ali read the book.'
Not: 'Ali read the books.'

One might wonder whether it is still possible to keep the number neutral analysis and derive the singular interpretations via a competition story. In line with this idea, Bale et al. (2010) claim that Turkish bare plurals are exclusive of atoms in denoting pluralities only (see also Görgülü 2012). Namely, the bare plural kitaplar 'books' denotes the set $\{a \oplus b, b \oplus c, a \oplus c, a \oplus b \oplus c\}$ in their view. Maintaining this analysis, one might argue that the competition between number neutral bare singulars and strict plurals results in the singular reading of bare singulars as in (6). However, bare plurals in Turkish are actually inclusive of atoms and their pluralities just as in English, i.e. $\{a, b, c, a \oplus b, a \oplus c, b \oplus c, a \oplus b \oplus c\}$, as I will show below. ${ }^{3}$

Krifka (2003), Sauerland et al. (2005), Spector (2007), and Zweig (2009) argue for a number neutral account of bare plurals in English. In these works, it has been observed that although bare plurals contain multiplicity as part of their denotation in positive contexts, they lose that requirement in downward entailing and question contexts. In other words, the 'more than one' meaning does not seem to be a strict requirement in their interpretation. It has been claimed that this is due to the number neutral denotation that they have, the multiplicity condition of which arises as a result of a conversational (scalar) implicature in positive contexts. So, a bare plural in English denotes a set of atomic individuals and pluralities.

This observation also holds for Turkish bare plurals as evidenced by the example in (7). If we had gone to the forest and come across one bear, it would be bizarre to respond to the question in (7) as 'no'. Because seeing one bear is an efficient answer to the question in (7), the denotation of the bare plural ayllar cannot be 'more than one' bear.

$$
\begin{aligned}
& \text { Orman-da ayı-lar-a rastla-dı-nız mi? } \\
& \text { forest-LOC bear-PL-DAT come.across-PAST-2PL Q } \\
& \text { 'Did you come across bears in the forest? }
\end{aligned}
$$

\footnotetext{
${ }^{3}$ See Renans et al. (2017) for an experimental study showing the number neutrality of Turkish plurals.
} 

a. Evet, bir tane gör-dü-k. yes, one CL see-PAST-1PL 'Yes, we saw one.
b. \#Hayır, bir tane gör-dü-k. no, one CL see-PAST-1PL 'No, we saw one.'

Now, consider (8b) where a bare plural appears in a negative context. In (8a), the scalar implicature surfaces since the 'more than one' interpretation is stronger than the 'one or more' interpretation. On the other hand, (8b) is felicitous when there are no children playing ball, but not if there is only one child playing, as would be predicted by a strictly plural account.
a. Çocuk-lar sokak-ta top oynu-yor.
child-PL street-LOC ball play-PROG
'Children are playing ball on the street.'
b. Çocuk-lar sokak-ta top oyna-mi-yor.
child-PL street-LOC ball play-NEG-PROG
'Children aren't playing ball on the street.'

The 'one or more' reading of bare plurals is also available in other downward entailing contexts such as the antecedents of the conditionals as in (9a) and the restrictors of universal quantifiers as in (9b). In both cases, the bare plural erkekler 'men' is interpreted neutrally. ${ }^{4}$
a. Eğer erkek-ler tarafından aldatıldıysan, sen de biz-e katıl-abil-ir-sin. if man-PL by were.cheated you also we-DAT join-ABIL-AOR-2SG 'If you have been cheated by men, you can join us.' (one or more men)
b. Erkek-ler tarafından aldatılan herkes biz-e katıl-abil-ir. man-PL by was.cheated everybody we-DAT join-ABIL-AOR. 'Everyone who has been cheated by men can join us.' (one or more men)

Therefore, in light of the argumentation for English bare plurals, I argue that Turkish bare plurals are also number neutral and the multiplicity condition in positive contexts arises as a result of a conversational implicature.

Bale et al. (2010) use the following sentences in (10) as evidence for their strict plural account of Turkish bare plurals (pg. 8). The reasoning is as follows: If plurals were inclusive of atoms, then they would be expected to be predicated of singular subjects as well as plural ones. The example in (10b) shows that plurals in Turkish cannot be predicated of singular subjects.

$$
\begin{aligned}
& \text { a. John ve Brad çocuk(-lar). } \\
& \text { John and Brad child-PL } \\
& \text { 'John and Brad are children.' }
\end{aligned}
$$

\author{
b. *John çocuk-lar. \\ John child-PL \\ Intended: 'John is a child.'
}

However, -lAr in (10a) is not the genuine plural marker but the optional 3rd person plural agreement, which happens to be homophonous with the former. One way to distinguish the two is their stress pattern. The third person plural marker shifts the stress to the preceding syllable, whereas the genuine plural marker itself bears the stress (Göksel and Kerslake 2005). In (10a), the stress is on the syllable preceding - $l A r$, suggesting that it is the 3rd person plural agreement

\footnotetext{
${ }^{4}$ The bare plurals in (7), (8), and (9) can also be interpreted as definites. See Section 3.2.1 for details.
} 
marker. Given that, the structure of (10a) can be roughly represented as the following: ${ }^{5}$

$$
\text { [TP John ve Brad [VP [NP çocuk] COP] T+-lar }]
$$

We expect (10b) to be bad because the subject is not plural, so the 3rd person plural agreement is not realized on the predicate.

If (10a) is pronounced with the stress on $-l A r$, then the sentence means 'John and Brad are the children.', not 'John and Brad are children.', receiving an equative interpretation. We still expect (10b) to be bad since the equative reading requires a maximal unique plural individual to be equated with the children. The subject John, however, is an atomic individual. So, there is a number mismatch between the two entities that are equated. ${ }^{6}$

To wrap up, we have seen that bare singulars denote sets of atoms and bare plurals are number neutral, inclusive of atoms and pluralities.

\subsection{Singularity in kinds}

In this section, I show that besides denoting atomic properties, bare singulars can also have singular kind reference following Dayal's (2004) view on English definite singular kinds. This constitutes further evidence for their atomic property denotation. I will first discuss the properties of kinds by introducing plural kinds in Turkish and then return to singular kinds.

\subsubsection{Overview of kind terms}

We have seen that Turkish bare plurals are like English bare plurals in being number neutral. They are also equivalent in having the following primary readings: kind (12a), generic (12b), and existential (12c) (see Carlson 1977 and Chierchia 1998 for English bare plurals):

\footnotetext{
a. Dinazor-lar 66 milyon 38 bin y1l önce yok ol-du. dinosaur-PL 66 million 38 thousand year ago extinct be-PAST 'Dinosaurs became extinct 66 million 38 thousand years ago.'

b. Ayı-lar genelde saldırgan ol-ur. bear-PL usually aggressive be-AOR 'Bears are generally aggressive.'

c. Kedi-ler dişarda çiftleş-iyor. cat-PL outside mate-PROG 'Cats are mating outside.'/ 'The cats are mating outside.'
}

\footnotetext{
${ }^{5}$ Kornfilt (1996) and Kelepir (2003) claim that there is a null realization of the copula (COP) - $i$ between the noun and the person agreement marker. The copula, being a clitic, shifts the stress to the preceding syllable.

${ }^{6}$ This is achieved by a competition with the singular definite denoted by the singular form due to Maximize Presupposition (MP, Heim 1991). Recall that bare singulars are interpreted as singular in definite readings.
} 
I suggest following Chierchia (1998) and Dayal (2004) that bare plurals start as type $<\mathrm{s},<\mathrm{e}, \mathrm{t}\rangle>$ and become kind terms of type $<$ s,e $>$ via nominalization operation (nom), i.e. $\cap: \lambda P_{<s, e t>} \lambda s$ $\imath x\left[P_{s}(x)\right] .\left(P_{s}\right.$ is the extension of $P$ at a situation $s$.) This implies that bare plurals can directly combine with kind-level predicates. When they combine with object-level predicates, further operations come into the picture (Chierchia, 1998). One is the inverse of nom, predicativization (pred), which takes the extension of the kind and returns the set of singular and plural entities that are the instantiations of the kind (in line with the neutrality of bare plurals), i.e. $\cup: \lambda k_{\langle s, e>}$ $\lambda x\left[x \leq \mathrm{k}_{s}\right]$. ( $k_{s}$ is the plural individual consisting of atomic members of the kind.) In generic contexts, the Generic operator quantifies over these instantiations. The other is Derived Kind Predication (DKP), which provides sort adjustment and introduces $\exists$-quantification over the instantiations of the kind provided by pred in a given situation in episodic contexts.

DKP: If $P$ applies to objects and $k$ denotes a kind, then $P(k)=\exists x[\cup k(x) \wedge P(x)]$

The application of DKP also results in narrow scope interpretation of bare plurals, as in English:

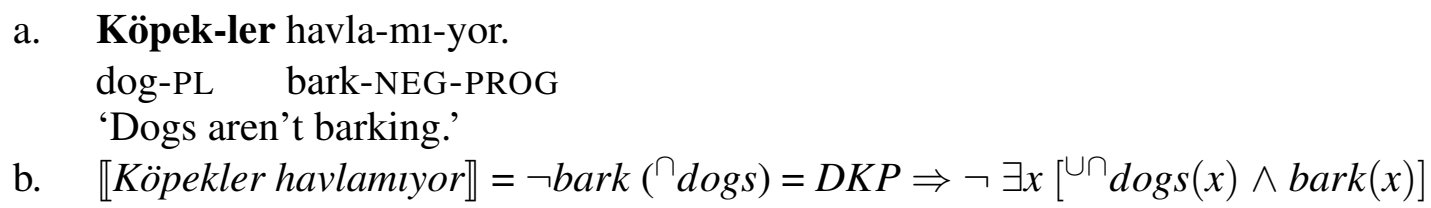

The fact that plural kinds are transparent to their instantiation sets is supported by the tests showing that access to the atomic level is necessary in object level readings (Schwarzschild, 1996). Below, among such tests the compatibility with reciprocals and the predicate come from different areas are applied. ${ }^{7}$ The compatibility of bare plurals with these tests shows that plural kinds have a see-through relation with their instantiations, since the atomic level of a kind term is accessible only if its instantiations are grammatically available. (15a) and (15b) exemplify generic and episodic contexts, respectively.

\footnotetext{
a. Kedi-ler birbiri-ne saldir-1r.

cat-PL each.other-DAT attack-AOR

'Cats attack each other.'
}

b. Ayı-lar bu hayvanat bahçesi-ne farklı bölge-ler-den gel-di. bear-PL this zoo-DAT different area-PL-ABL come-PAST 'Bears came to this zoo from different areas.'

Differently from English ones, Turkish bare plurals can also have definite interpretations in object-level contexts besides narrow scope existential readings as is evident in the example (12c). This difference comes from the fact that Turkish lacks an overt definite article and we assume that the definite interpretations are achieved by covert type-shifting via iota. This makes bare plurals in Turkish ambiguous between narrow scope existential and definite readings. ${ }^{8}$

\footnotetext{
${ }^{7}$ Schwarzschild (1996) uses the incompatibility of collective/group-denoting nouns with reciprocals and the predicate live in different cities to show that collective nouns do not allow access to atoms.

${ }^{8}$ Nom and iota can freely apply in Turkish because there are no overt versions that would block them. This is a consequence of the Blocking Principle proposed in Chierchia (1998) which is represented below.

(i) Blocking Principle: For any type shifting operation $\phi$ and for any $X$ : $* \phi(X)$ if there is a Determiner D
} 


\subsubsection{Singular kinds}

What about bare singulars? Just like bare plurals, they can also combine with kind level and generic predicates as shown in (16a) and (16b). However, in episodic contexts, they are interpreted as strictly singular and definite as shown in (16c). This contrasts with bare plurals, which can receive narrow scope existential readings as in (12c).
a. Dinazor 66 milyon 38 bin yil önce yok ol-du. dinosaur-PL 66 million 38 thousand year ago extinct be-PAST 'The dinosaur became extinct 66 million 38 thousand years ago.'
b. Ayı genelde saldırgan ol-ur. bear usually aggressive be-AOR 'The bear is generally aggressive.'
c. Kedi dışarda çiftleş-iyor.
cat outside mate-PROG
'The cat is mating outside.' Not: '(The) Cats are mating outside.'

The lack of existential readings with bare singulars is further shown by their inability to take scope under negation as illustrated in (17), where the only interpretation available is singularity and definiteness. This behavior of bare singulars would not be expected if they were kind terms the way plural kinds are, hence if their instantiations included atoms and pluralities. Namely, like plural kinds they would be derived by nom, and in episodic contexts they would get number neutral existential readings by DKP. Given their singularity and definiteness in episodic contexts, how bare singulars can have kind denotations seems to be mysterious considering the view that kinds are inherently plural entities (Chierchia, 1998).
Kedi dişarda çiftleş-mi-iyor.
cat outside mate-NEG-PROG
'The cat isn't mating outside.'

We can understand the behavior of bare singulars if we take them to be more like definite singular kinds in English (e.g. The lion is extinct.). Dayal claims that even though kinds (singular or plural) are conceptually plural, singular kinds are grammatically atomic. They are different from plural (and mass) kinds in not having a semantically transparent relation to their instantiations. Namely, they are impure atomic in the sense of Link (1983) and Landman (1989) behaving more like a collective noun. This means that pred or any similar operators like Carlson's (1977) Realization $(R)$ relation are undefined for singular kinds. The latter constitutes the relation between kinds and their instantiations, i.e. $R(x, y)$ where $y$ is a kind and $x$ is an individual instantiated by that kind. ${ }^{9}$ Hence, DKP is also unavailable for them.

such that for any set $X$ in its domain, $D(X)=\phi(X)$.

In English, iota cannot freely apply to bare nouns since it is blocked by the overt definite marker the. Bare plurals in Turkish cannot get strong indefinite interpretations due to the Meaning Preservation which is proposed in Chierchia (1998), but revised in Dayal (2004). According to the Revised Meaning Preservation, nom and iota are ranked above the existential operator, hence nouns in Turkish can shift via the former but not the latter.

(ii) Revised Meaning Preservation: $\{\cap, \imath\}>\exists$

${ }^{9}$ By abstracting over $x$, we would be able to get the instantiation set of a singular kind. This way they would not 
Dayal's claim is based on the idea that common nouns systematically denote properties of ordinary individuals and properties of (sub-)kinds. Just like other determiners such as every and $a$, when the definite determiner combines with the latter it yields taxonomic readings. Namely, the definite singular kinds are derived compositionally from the regular definite determiner and a common noun denoting a taxonomic property, i.e. $\imath X[P(X)], X$ ranging over taxonomic entities. Based on that, lion in 'The lion is extinct' denotes a singleton set containing the unique lion kind, i.e. $\{L I O N\}$, if the domain of quantification is the set of taxonomic entities as LION, WHALE, etc. (excluding types of lions). The definite, the lion, denotes its singleton element.

Singular definite kinds in English are not compatible with object-level contexts (episodic as well as generic) unless the statement is applicable to the whole species (e.g. The rat reached Australia in 1770.). In other words, they are impure atomic terms whose only instantiation set (if available at all) includes a singular representative or prototypical object.

The same facts hold for singular kind terms in Turkish. ${ }^{10}$ Since Turkish lacks an overt definite marker, they are realized in bare form to which the covert iota operator applies. ${ }^{11}$ I also provide further evidence with respect to their impure atomicity by applying the tests for the accessibility of the atomic level. Consider (18) where the bare singular ayı is used in an episodic context and is incompatible with the distributive predicate come from different areas (cf. with (15b)).

\footnotetext{
*Ayı bu hayvanat bahçesi-ne farklı bölge-ler-den gel-di. bear this zoo-DAT different area-PL-ABL come-PAST

Intended: 'Bears came to this zoo from different areas.'
}

The sentence in (18) shows that singular kinds do not allow distributive predication to entities we intuitively associate with them. Otherwise, they would be interpreted like plural kinds and yield grammatical results with these tests. Since singular kinds are impure atomic, the denotations of bare singulars in object-level contexts as in (16c) must be derived without reference to their kind denotations. More precisely, they denote atomic properties independent of being singular kinds. In cases like (16c), iota combines with the atomic property denotation of bare singulars to yield singular definite interpretations. ${ }^{12}$ However, as in English, if a singular kind in Turkish refers to the totality of species as a prototypical object, it is compatible with object-level predicates as in (19).

$$
\begin{aligned}
& \text { Bilgisayar bu ülke-ye çok geç gel-di. } \\
& \text { computer this country-DAT very late come-PAST } \\
& \text { 'The computer reached this country very late.' }
\end{aligned}
$$

Similarly, in generic statements, singular kinds are acceptable again if they refer to the whole species as a prototypical object explaining their compatibility with genericity as in (16b). The fact that singular kinds block access to their instantiations also holds for generic contexts, as

\footnotetext{
be different from plural kinds.

${ }^{10}$ I consider singular kinds in Turkish to be names of kinds, so they have the same denotation in every situation, like proper names. See Section 3.3.2.

${ }^{11}$ This is also the case in languages like Russian and Hindi as shown in Dayal (2004).

${ }^{12}$ Strong indefinite readings are not available for bare singulars due to Revised Meaning Preservation.
} 
evidenced by their incompatibility with reciprocals (cf. with (15a)).

$$
\begin{aligned}
& \text { *Kedi birbiri-ne saldir-1r. } \\
& \text { cat each.other-DAT attack-AOR } \\
& \text { Intended: 'Cats attack each other.' }
\end{aligned}
$$

To summarize, plurals are kinds and their object-level interpretations are derived via pred and DKP. On the other hand, bare singulars are ambiguous in being singular kinds and independently denoting atomic properties. In object-level contexts, their atomic property denotations are made use of unless a prototypical representation of the kind is meant. This is in line with the lack of narrow scope existential readings with them and their singular interpretations.

To wrap up the discussion so far, we have seen two types of evidence showing that bare singulars in Turkish denote sets of atoms. One was their singularity in argument positions and the other was their singular kind denotations.

\subsection{Explaining neutrality}

In this section, I will explain the apparent number neutrality of bare singulars in non-case marked direct object (21a) and predicate positions (21b), both of which stem from their singular kind denotations. The corresponding sentences in (5b) and (5a) are repeated below.

a. Ali kitap oku-du.

Ali book read-PAST

'Ali did book-reading.' b. Ali ve Merve çocuk.

Ali and Merve child

'Ali and Merve are children.'

\subsubsection{Pseudo-incorpration}

Öztürk (2005), following Massam (2001), claims that non-case marked bare singulars occupying a direct object position immediately preceding the verb undergo pseudo-noun incorporation (PI). The semantics of PI has been the focus of a number of accounts (e.g. van Geenhoven 1998, Farkas and De Swart 2003, and Dayal 2011, among others), all of which agree in that pseudoincorporated (PI-ed) nouns are property denoting. Among them, Dayal (2011) claims that they simply modify the verb, the result of which denotes predicate of events- subtypes of the events.

Inspired by the analysis of the weak definites of English in Aguilar-Guevara and Zwarts (2010) (e.g. Lola is reading the newspaper.), I argue that Turkish PI-ed bare singulars take part in sub-event kinds in line with Dayal (2011), but as singular kind arguments instead of properties. Their number neutrality is an inference due to the conceptual plurality of singular kinds.

The claim that PI-ed bare singulars are arguments instead of modifiers comes from the fact that they block the occurrence of an extra object with the same thematic role as they bear. (This contrasts with Chamorro where theme-doubling is possible (Chung and Ladusaw, 2004).) 
*Ali Savaş ve Barış(-1) kitap oku-du.

Ali war and peace-ACC book read-PAST

Intended: 'Ali did book-reading War and Peace.'

The claim that PI-ed bare singulars are singular kinds instead of properties is supported by the following facts. First of all, they are interpreted neutrally although we have previously seen that their property denotation is atomic. ${ }^{13}$ Second, modification is incompatible with them, requiring indefinite or plural forms, unless it is meant to operate at the taxonomic domain, establishing sub-kinds. ${ }^{14}$ Consider the following contrast:

$$
\begin{aligned}
& \text { a. *Ali eski kitap oku-du. } \\
& \text { Ali old book read-PAST } \\
& \text { 'Ali read an old book/old books.' }
\end{aligned}
$$

b. Ali teknik kitap oku-du.

Ali technical book read-PAST 'Ali did technical book-reading.'

This contrast stems from the fact that singular kinds are built on taxonomic properties, not the ones of ordinary objects. (23a) is bad because the adjective old can be considered as operating at the level of ordinary objects with a meaning like worn-out or old in terms of its publication date, whereas the adjective technical in (23b) defines a sub-kind of the book kind, hence it is compatible with the PI-ed singular kind. ${ }^{15}$ Since singular kinds are impure atomic terms their instantiation sets are not available. Therefore, they cannot be type-shifted to sets of individuals suitable for modification by adjectives like eski 'old'.

Finally, PI-ed bare singulars are non-referential at the ordinary object level as shown in (24a) (Öztürk 2005: pg. 27), but reference to the kind itself is possible as shown in (24b). (Both examples are meant to follow (21a).) This is expected since PI-ed bare singulars are kind terms, so they introduce discourse referents at the level of kinds, not ordinary objects. DKP is also not available for singular kinds. Otherwise, they would be referential at the ordinary object level via $\exists$-quantification introduced by it.

$$
\begin{aligned}
& \text { a. \#Reng-i kirmızi-y-d1. } \\
& \text { color-3POSS red-COP-PAST } \\
& \text { 'Its/Their color was red.' }
\end{aligned}
$$
b. Polisiye türü-y-dü.
crime kind-COP-PAST
'It (the book kind) was crime.'

In summary, based on their syntactic argument status and the facts given above, I claim that PI-ed bare singulars are singular kind arguments.

I follow the view that there are event kinds as well as event tokens in the ontology as pursued in Schäfer (2007) and Gehrke and Mcnally (2011) (and references therein). I assume that event

\footnotetext{
${ }^{13}$ Dayal (2011) argues that Hindi PI-ed bare singulars denote atomic properties, but number neutrality is achieved as a result of their interaction with atelicity. I have pursued this idea for Turkish previously as presented in the talk, but later realized that singularity is not necessitated in all telic contexts. For reasons of space, I will not discuss this issue.

${ }^{14}$ Taxonomic modification is usually available with adjectives rather than more complex structures like relative clauses. It is because adjectives are considered to be providing natural classification as opposed to the others which are mostly restricted to temporal, stage-level modications (Sadler and Arnold, 1994). However, depending on the context, relative clauses can also be taxonomic.

${ }^{15}$ The sentence can be acceptable if oldness defines a sub-kind of the book kind with a meaning like 'ancient/historical' kind of books. In addition, for some speakers (23a) is good but only with a singular interpretation.
} 
kinds are derived via nom (by a mereological treatment of events). Nom is considered to be a general operator also applying to events as a function from event properties to situations, from situations to the maximal event satisfying that property in that situation, i.e. $\lambda P_{<s, v t>} \lambda s$ ve $\left[P_{s}(e)\right]$ (iota yielding the largest plurality of events here). Similarly, pred applies to event kinds and returns sets of event tokens in a given situation, i.e. $\lambda k_{<s, v>} \lambda e\left[e \leq k_{s}\right]$.

For example, the reading event kind is given in (25a) which is derived by the application of $n o m$ to the reading event property $\lambda s \lambda e\left[R E A D_{s}(e)\right]$, and the reading event token is given in (25b) which is derived by the application of pred to the reading event kind.

$$
\begin{array}{ll}
\text { a. } & \llbracket \text { read }^{\text {kind }} \rrbracket=\cap \lambda s \lambda e\left[\operatorname{READ}_{s}(e)\right]=\lambda s i e\left[\operatorname{READ}_{s}(e)\right] \\
\text { b. } & \llbracket \text { read }^{\text {token }} \rrbracket=\cup \lambda s \imath e\left[\operatorname{READ}_{s}(e)\right]=\lambda e^{\prime}\left[e^{\prime} \leq \imath e\left[\operatorname{READ}_{s}(e)\right]\right]
\end{array}
$$

Nom can also apply to an event property of $\langle\mathrm{s},<\mathrm{v}, \mathrm{t}\rangle>$ type that has a singular kind as its theme, e.g. $\lambda s \lambda e\left[R E A D_{s}(e) \wedge T h_{s}(e)=\imath X[B O O K(X)]\right]$, and the result of this application will denote a sub-event kind as shown in (26).

$$
\begin{aligned}
\llbracket \text { book-read }{ }^{k i n d} \rrbracket & =\cap \lambda s \lambda e\left[R E A D_{s}(e) \wedge T h_{s}(e)=\imath X[B O O K(X)]\right] \\
& =\lambda s \imath e\left[R E A D_{s}(e) \wedge T h_{s}(e)=\imath X[B O O K(X)]\right]
\end{aligned}
$$

I argue that this sub-event kind forming process is PI. The singular kind book does not refer to any actual books, and its role is to restrict the denotation of the reading event kind by participating in it as a theme argument. This participation in return will yield a book-reading event kind, which is a sub-kind of the reading event kind. In other words, PI is a process where the taxonomy of event kinds is determined by thematic arguments.

Consecutively, the book-reading event kind will undergo pred, which results in a set of event tokens, as shown in (27a). Then, this set of event tokens will take an agent argument and be existentially closed as shown in (27b) (ignoring tense).

$$
\begin{aligned}
& \text { a. } \quad \llbracket \text { book-read }{ }^{\text {token }} \rrbracket=\cup \lambda s \text { ie }\left[R E A D_{s}(e) \wedge T h_{s}(e)=\imath X[B O O K(X)]\right] \\
& =\lambda e^{\prime}\left[e^{\prime} \leq \imath e\left[R E A D_{s}(e) \wedge T h_{s}(e)=\imath X[B O O K(X)]\right]\right] \\
& \text { b. } \llbracket \text { Ali book-read }{ }^{\text {token }} \rrbracket=\exists e^{\prime}\left[e^{\prime} \leq \imath e\left[R E A D_{s}(e) \wedge T h_{s}(e)=\imath X[B O O K(X)]\right]\right. \\
& \left.\wedge A g\left(e^{\prime}\right)=A l i\right]
\end{aligned}
$$

Here, Ali is involved in an instance of the book-reading event kind. The assertion that at least one episodic event token of this event kind exists will correspond to the inference of reading one or more books which are the instantiations that the singular kind is conceptually associated with. ${ }^{16}$ This explains the number neutral interpretation of PI-ed bare singulars. ${ }^{17}$

As a final remark, nom will be undefined for event properties with non-kind arguments. For

\footnotetext{
${ }^{16}$ Mithun (1984) shows that kind-referring nouns are normally incorporated in languages that make use of incorporation. Following Mithun, Krifka et al. (1995) argue that incorporated nouns refer to kinds, and noun incorporation is a syntactic device to stay in the kind-oriented mode.

${ }^{17}$ Additionally, subject PI is also available as shown by Öztürk (2005), e.g. Ali-yi arl soktu 'Ali got bee-stung'. I will not go into the details here but I argue that they also fall into the same analysis proposed for object PI.
} 
example, it will be hard to impute to a reading this book event a sufficiently regular behavior so that it can qualify as an event kind (see Chierchia 1998). Instead, such arguments are introduced within event tokens, and they do not participate in (sub-)event kind formation. ${ }^{18}$

In summary, the aim of this section has been to show that bare singulars occurring as non-case marked objects are singular kinds that participate in sub-event kind formation. Their number neutral interpretation is an inference due to the conceptual plurality of singular kinds.

\subsubsection{The predicate position}

Finally, I will discuss the number neutrality of bare singulars appearing in the predicate position. Analogous to the analysis of pseudo-incorporation, I claim that bare singulars in the predicate position can be singular kinds, and the apparent neutrality follows from that.

To recall, bare singulars can be predicated of plural subjects besides singular ones as exemplified in (21b), which seems to suggest that they denote number neutral sets. However, closer investigation reveals that this is not the case. Namely, when bare singulars in the predicate position are modified they are only compatible with singular subjects as shown in (28). Interestingly, though, if the adjectival modifier establishes a sub-kind/type of the noun that it modifies then the predication is also compatible with plural subjects as shown in (29).
a. Ali yakışıklı doktor.
Ali handsome doctor
'Ali is a handsome doctor.'
b. *Ali ve Mehmet yakışıklı
Ali and Mehmet handsome

\section{doktor.}

doctor

\section{a. Ali pratisyen doktor. \\ Ali practitioner doctor \\ 'Ali is a practitioner doctor.' \\ b. Ali ve Mehmet pratisyen \\ Ali and Mehmet practitioner \\ doktor.}

doctor

The former case can be explained by the claim that bare singulars denote atomic properties, and they can be modified at the ordinary object level. Additionally, since they are atomic properties, they can only be predicated of singular subjects.

On the other hand, the latter case reminds us of the modification facts of PI. In parallel with this, the contrast given above can be attributed to the view that bare singulars can also appear as singular kinds in the predicate position, being only compatible with taxonomic modification. ${ }^{19}$ However, how can singular kinds occur in the predicate position in the first place? We have previously discussed their impure atomicity which suggests that any type-shifting operation that would take a singular kind and return its instantiation set is not available. Therefore, predication is impossible in this way.

\footnotetext{
${ }^{18}$ Öztürk (2005) claims that case assignment is not achieved by verbs but higher functional heads. Unlike canonical arguments introduced by the latter, PI-ed bare singulars do not receive case since they are complements to verbs.

${ }^{19}$ Bare singulars in the predicate position can also be found in Romance and Germanic languages like Dutch, French, Spanish, and German, although their usage is more restricted compared to the ones in Turkish. See de Swart et al. (2007) for an account of them which is in similar lines with the analysis given here.
} 
Instead, I propose that the usage of singular kinds in the predicate position is a process of naming the subject term with respect to a kind that it belongs to. This is achieved by the copula that plays the role of a null operator associating the two. The denotation that the copula has in such structures is given in (30a), and the logical form of the sentence Ali çocuk 'Ali is child' is represented in (30b). ( $k$ represents kinds, $K$ represents singular kinds, $R$ is Carlson's Realization relation, and NAME is a relation constituting the relation between kinds and their names.) Informally, (30b) can stated as the following: There is a kind that Ali is a member of, and that kind is named as $\imath X[C H I L D(X)]$ (the singular kind child).

$$
\begin{array}{ll}
\text { a. } & \llbracket C O P \rrbracket=\lambda x^{K} \lambda y \exists k\left[R(y, k) \wedge N A M E\left(k, x^{K}\right)\right] \\
\text { b. } & \llbracket \text { Ali is child } \rrbracket=\exists k[R(A l i, k) \wedge N A M E(k, \imath X[C H I L D(X)])]
\end{array}
$$

The motivation behind this claim is that singular kinds are names of kinds, as opposed to plural ones in Turkish. This is supported by the dediğin 'that you call' construction, with which you refer to the kind term by what you call it as exemplified below. It is only good with singular kinds, not with plural ones, suggesting that the kind-naming construction is only expected to be compatible with singular kinds. ${ }^{20}$

$$
\begin{aligned}
& \text { Bilgisayar(*-lar) dediğin Charles Babbage tarafından icat ed-il-di. } \\
& \text { computer-PL that.you.call Charles Babbage by invent-PASS-PAST } \\
& \text { Literally: 'The kind that you call the computer was invented by Charles Babbage.' }
\end{aligned}
$$

The kind-naming specification can also be achieved if the subject is a plural term considering that sum individuals can also be members of kinds. This explains the compatibility of bare singulars with plural subjects in the predicate position. The logical form of (21b) is given below, which can be informally stated as the following: There is a kind that the plural individual Ali $\oplus$ Merve is a member of, and that kind is named as $\imath X[C H I L D(X)]$.

$$
\llbracket \text { Ali and Merve are child } \rrbracket=\exists k[R(\text { Ali } \oplus \text { Merve }, k) \wedge N A M E(k, \imath X[C H I L D(X)])]
$$

To wrap up, bare singulars in the predicate position can be singular kinds and their compatibility with plural subjects comes from the null kind-naming specification.

\section{Back to Counting: The Semantics of the Classifier tane}

So far, we have seen that the property denotation of bare singulars in Turkish is atomic, which is in line with I\&M's view of numerals where they are argued to be modifiers of type $<<\mathrm{e}, \mathrm{t}>,<\mathrm{e}, \mathrm{t}>>$ that combine with atomic properties. $^{21}$ This way we can explain the grammaticality of constructions where a numeral is followed by a bare singular, instead of a bare plural (e.g. iki kitap 'two book', *iki kitap-lar 'two book-PL'). ${ }^{22}$ Let us now discuss the role of

\footnotetext{
${ }^{20}$ This seems to be a language specific property, as the so called construction in English which can be considered similar to the dediğin construction is fine with both singular and plural kinds as observed by Carlson (1977).

${ }^{21}$ In Turkish çok 'many/a lot of' and bir kaç 'a few' also combine with bare singulars rather than bare plurals. I suggest that they can also be considered to presuppose atomicity like numerals.

${ }^{22}$ Some numeral constructions of Turkish can have plural marking on them, e.g. Nice 20 yil-lar-a! 'To multiple 20 years! (Cheers!)', and yedi cüce-ler 'the seven dwarfs'. In the former, the plural marker pluralizes the denotation
} 
the classifier tane in numeral constructions.

Classifiers are widely thought to be a means of mediating between the denotation of a noun and the numeral in obligatory classifier languages like Chinese. Krifka (1995) and Chierchia (1998) propose that classifiers are functions from kinds into sets of atoms constituted by the instantiations of the kind, i.e. $\lambda x^{k} \lambda y\left[{ }^{\cup} x(y) \rightarrow A T(y)\right]$. Nouns in such languages uniformly denote kind terms of $<\mathrm{s}, \mathrm{e}>$ type as they come out of the lexicon. Since kinds are inherently plural being equal to mass nouns in some sense, their atomic instances are not available for counting. Therefore, classifiers are required in order to reach the atomic level of the kind.

This view cannot be adopted for tane, though. Otherwise, it would be obligatorily attested with plural kinds, but plurals cannot occur in numeral constructions and tane is not compulsory. (Singular kinds would not be an option due to their impure atomic nature.) Instead, I propose that tane is a partial identity function which triggers a presupposition for atomic properties just like numerals. ${ }^{23}$ I also treat it as taking numerals (represented by $f$ ) as one of its arguments ${ }^{24}$.

$$
\llbracket \text { tane } \rrbracket=\lambda P_{<e t>} \lambda f_{<e t, e t>}: \forall x[P(x) \rightarrow A T(x)] . f(P)
$$

This account immediately explains the grammaticality of constructions with the classifier which combine with a bare singular, but not a bare plural (e.g. iki tane kitap 'two CL book', *iki tane kitap-lar 'two CL book-PL'). The optionality of the classifier is a consequence of the fact that, besides numerals that can directly combine with atomic properties, the language has also a partial identity function that takes both numerals and atomic properties as its arguments.

As an optional element, the classifier seems to be redundant in the language. However, there are contexts in which it is obligatory. Contra English, ellipsis of the noun is impossible unless the numeral is accompanied by the classifier. This is also the case in partitive constructions.

$$
\begin{aligned}
& \text { a. İki } *(\text { tane) elma verir mi-sin? } \\
& \text { two CL apple give Q-2SG } \\
& \text { 'Can you give me two (apples)?' }
\end{aligned}
$$
b. Elma-lar-dan iki *(tane) elma apple-PL-ABL two CL apple 'two of the apples'

Now let me discuss a possible hypothesis regarding the obligatoriness of the classifier in (34a) and (34b). I follow Lobeck (1995) (for (34a)) and Ionin et al. (2006) (for (34b)) in taking such structures to involve a null (deleted) noun which needs licensing by a head (proper headgovernment). I suggest that numerals in Turkish are in the specifier of the nominal projection as shown in (35) contra numerals in English which are claimed to take the NP as a complement in Lobeck (1995) and I\&M as shown in (35c). ${ }^{25}$ Due to their non-head status, the former cannot

of the numeral construction 20 yillar '20 years' referring to more than one instance of 20 years. This means that it is still the genuine plural marker, rather than agreement. The latter is not a canonical numeral construction, and the numeral is just a modifier to the plural noun, denoting the most specific property of the dwarfs, i.e. being seven in number. Such structures are only possible with well-known groups (e.g. the three muskeeters).

${ }^{23}$ Thanks to Veneeta Dayal for suggestions to explore this idea. Note that Bangla - $r a$ is analyzed as a classifier that encodes a presupposition in Dayal (2014).

${ }^{24}$ We do not have strong evidence with regards to the order of the combination.

${ }^{25}$ In I\&M, languages where numerals assign case to their nominal complements are argued to have the structure in (35c). Although English numerals do not pattern with this, they prefer to posit the same structure for them. The 
license the elided NP. In the presence of the classifier the NP is extended by its projection as shown in (35b), so the elided noun is licensed by the classifier. ${ }^{26}$

a.

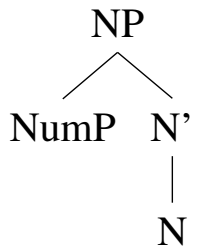

b.

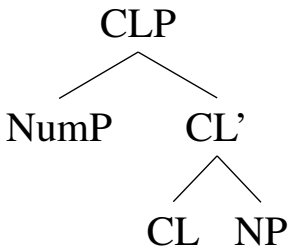

c.

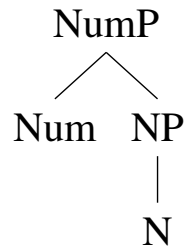

The requirement for the classifier in ellipsis structures is also a property found in other optional classifier languages like Persian. This observation calls for further inquiry, but for now, it provides an interesting new dimension to our analysis of optionality in the Turkish classifier system. ${ }^{27}$

In summary, the classifier in Turkish is a partial identity function that presupposes atomic properties, which, combined with I\&M's account of numerals, explains its optionality. The derivations of the numeral constructions are summarized below:

$$
\begin{aligned}
& \text { a. } \llbracket 2 \text { book } \rrbracket=\lambda x \exists S[\Pi(S)(x) \wedge|S|=2 \wedge \forall s \in S \operatorname{book}(s)] \\
& \text { b. } \llbracket 2 \text { tane book } \rrbracket=\lambda x: \forall x[P(x) \rightarrow A T(x)] . \exists S[\Pi(S)(x) \wedge|S|=2 \wedge \forall s \in S \operatorname{book}(s)]
\end{aligned}
$$

\section{Conclusion}

In this paper, it has been argued that numerals in Turkish are modifiers of type $<<\mathrm{e}, \mathrm{t}\rangle,\langle\mathrm{e}, \mathrm{t}\rangle\rangle$, the lexical complement of which has to be atomic (Ionin and Matushansky 2006), contrasting with the account where they are treated as restrictive modifiers (Bale et al. 2010). It has been shown that bare singulars denote sets of atoms, and the classifier tane is a partial identity function presupposing atomic properties.

This analysis establishes that the denotations of nouns in Turkish align with the denotations of nouns in English in that bare singulars are strict singulars and bare plurals are number neutral. However, the two languages differ in the absence/presence of number agreement in numeral constructions, which is interpreted as cross-linguistic variation.

As a concluding remark, in order to situate the findings for Turkish within a broader context and to appropriately draw out the implications for natural language generally, further research

one suggested here for Turkish is not discussed in their paper, but it does not conflict with their semantic account of the numerals. In addition, because Turkish numerals do not assign case to nouns it is safe to assume a structure where numerals are in the spec of the nominal projections.

${ }^{26} \mathrm{CL}$ in (35b) is head-initial conflicting with the head-final property of Turkish. Instead, we can represent tane in the Spec, CLP assuming a null, head-final CL head. The crucial point is that NP is a part of CLP in the presence of CL, but it is not inside NumP.

${ }^{27}$ One can analyze the classifier as a semantically empty element having only a syntactic role. In such an analysis, the incompatibility of the classifier with plurals could be explained by the atomicity requirement of numerals. This approach is not adopted since they actually create a difference in meaning contributing an amount interpretation. The semantics of the classifier is still an ongoing project of mine and for present purposes, I want to preserve the role of the partial identity function for the classifier. 
on relevant facts from other optional classifier languages like Western Armenian, Persian, and Hungarian is called for.

\section{References}

Aguilar-Guevara, A. and J. Zwarts (2010). Weak definites and reference to kinds. Semantics and Linguistic Theory 20(0), 179-196.

Bale, A., H. Khanjian, and M. Gagnon (2010). Cross-linguistic representations of numerals and number marking. In Proceedings of SALT 20, pp. 1-15.

Bennett, M. R. (1974). Some Extensions of a Montague fragment of English. Ph. D. thesis, UCLA.

Carlson, G. N. (1977). Reference to Kinds in English. Ph. D. thesis, University of Massachusetts, Amherst.

Chierchia, G. (1998). Reference to kinds across language. Natural Language Semantics 6(4), 339-405.

Chung, S. and W. A. Ladusaw (2004). Restriction and Saturation. Cambridge, Mass.: MIT Press.

Dayal, V. (2004). Numer marking and indefiniteness in kind terms. Linguistics and Philosophy 27, 393-450.

Dayal, V. (2011). Hindi pseudo-incorporation. Natural Language and Linguistic Theory 29(1), $123-167$.

Dayal, V. (2014). Bangla plural classifiers. Language and Linguistics 15(1), 47-87.

de Swart, H. D., Y. Winter, and J. Zwarts (2007). Bare nominals and reference to capacities. Natural Language \& Linguistic Theory 25, 195-222.

Farkas, D. and H. De Swart (2003). The Semantics of Incorporation: From Argument Structure to Discourse Transparency. CSLI Publications.

Gehrke, B. and L. Mcnally (2011). Frequency adjectives and assertions about event types. In Proceedings of SALT 19, pp. 180-197.

Göksel, A. and C. Kerslake (2005). Turkish: A Comprehensive Grammar. London NY: Routledge.

Görgülü, E. (2012). Semantics of Nouns and the Specification of Number in Turkish. Ph.d. thesis, Simon Fraser University.

Heim, I. (1991). Artikel und definitheit. In A. V. Stechow and D. Wunderlich (Eds.), Semantics: An International Handbook of Contemporary Research, pp. 487-535. Berlin: de Gruyter.

Ionin, T. and O. Matushansky (2006). The composition of complex cardinals. Journal of Semantics 23(4), 315-360.

Ionin, T., O. Matushansky, and E. G. Ruys (2006). Parts of speech: Toward a unified semantics for partitives. In Proceedings of NELS 36, pp. 357-370.

Kelepir, M. (2003). Olmak, değil, var ve yok. In Proceedings of the XVIth Dilbilim Kurultay (National Linguistics Conference), pp. 70-81.

Kim, J. (2009). Plural Marking in Classifier Languages. Saarbrüken: VDM Verlag.

Kornfilt, J. (1996). On some copular clitics in Turkish. In A. Alexiadou, N. Fuhrhop, P. Law, and S. Loehken (Eds.), ZAS Papers in Linguistics, pp. 96-114. Berlin: Zentrum für Allgemeine Sprachwissenschaft 6.

Krifka, M. (1995). Common nouns: a contrastive analysis of Chinese and English. In The 
generic book, pp. 398-411. University of Chicago Press.

Krifka, M. (2003). Bare $\{\mathrm{NP}\}$ s: kind-referring, indefinites, both, or neither? In Proceedings of SALT 13, pp. 180-203.

Krifka, M., F. Pelletier, G. Carlson, A. ter Meulen, G. Chierchia, and G. Link (1995). Genericity: an introduction. In G. Carlson and F. J. Pelletier (Eds.), The Generic Book. Chicago: The University of Chicago Press.

Landman, F. (1989). Groups, I. Linguistics and Philosophy 12(5), 559-605.

Link, G. (1983). The logical analysis of plurals and mass terms: a lattice-theoretic approach. In P. Portner and B. H. Partee (Eds.), Formal Semantics - the Essential Readings, pp. 127-147. Blackwell.

Link, G. (1987). Generalized quantifiers and plurals. In Generalized Quantifiers: Linguistic and Logical Approaches, Studies in Ling. \& Philos.: 31, pp. 151-180. Reidel.

Lobeck, A. C. (1995). Ellipsis: Functional Heads, Licensing, and Identification. New York: Oxford University Press.

Massam, D. (2001). Pseudo noun incorporation in Niuean. Natural Language \& Linguistic Theory 19(1), 153-197.

Mithun, M. (1984). The evolution of noun incorporation. Language 60(4), 847-894.

Öztürk, B. (2005). Case, Referentiality, and Phrase Structure. Linguistics today. J. Benjamins Publishing Company.

Partee, B. H. (1987). Noun phrase interpretation and type-shifting principles. In Studies in Discourse Representation Theory and the Theory of Generalized Quantifiers, GroningenAmsterdam Studies in Semantics: 8, pp. 115-143. Foris.

Renans, Tsoulas, Folli, Ketrez, Tieu, de Vries, and Romoli (2017). Turkish plural nouns are number-neutral: experimental data. In Proceedings of the 21st Amsterdam Colloquium, pp. 365-374.

Sadler, L. and D. J. Arnold (1994). Prenominal adjectives and the phrasal / lexical distinction. Journal of Linguistics 30(1), 187-226.

Sauerland, U., J. Anderssen, and K. Yatsushiro (2005). The plural is semantically unmarked. Linguistic evidence 4, 409-430.

Schäfer, R. (2007). On frequency adjectives. In Proceedings of Sinn und Bedeutung 11, pp. $555-567$.

Schwarzschild, R. (1996). Pluralities. Springer.

Spector, B. (2007). Aspects of the pragmatics of plural morphology: on higher-order implicatures. In U. Sauerland and P. Stateva (Eds.), Presupposition and Implicature in Compositional Semantics, pp. 243-281. London: Palgrave Macmillan UK.

van Geenhoven, V. (1998). Semantic Incorporation and Indefinite Descriptions: Semantic and Syntactic Aspects of Noun Incorporation in West Greenlandic. Dissertations in Linguistics. Cambridge University Press.

Zweig, E. (2009). Number-neutral bare plurals and the multiplicity implicature. Linguistics and Philosophy 32(4), 353-407. 